\title{
APLIKASI PELAYANAN PROGRAM HAJI, UMRAH PRIORITAS DAN JADWAL KEBERANGKATAN DI KANTOR KEMENTERIAN AGAMA KABUPATEN BARITO KUALA
}

\author{
${ }^{1)}$ Fitrah Yuridka, ${ }^{2)}$ Zaenuddin, ${ }^{3)}$ Sefto Pratama \\ ${ }^{1}$ Fakultas Teknologi Informasi, Universitas Islam Kalimantan MAB (Fitrah Yuridka) \\ Email : vitrahyuridka@gmail.com, \\ ${ }^{2}$ Fakultas Teknologi Informasi, Universitas Islam Kalimantan MAB (Zaenuddin) \\ Email: Zaenuddin.uniska@gmail.com \\ ${ }^{3}$ Fakultas Teknologi Informasi, Universitas Islam Kalimantan MAB (Sefto Pratama) \\ Email: Seftopratama.bjm@gmail.com
}

\begin{abstract}
ABSTRAK
Kantor Kementrian Agama Kabupaten Barito Kuala terdiri dari beberapa bidang yang mempunyai tugas yang berbeda-beda dalam bidangnya masing-masing yaitu bidang haji dan umroh, bidang pendidikan madrasah, bidang pekapontren, bidang pendidikan agama islam, Bidang penyelenggara syari"ah, Zakat, dan wakaf dan bidang bimas (bimbingan masyarakat).

Dari beberapa bidang di atas ada satu bidang yang paling banyak berhubungan dalam segi pelayanan kepada masyarakat yaitu di bidang haji dan umroh, Haji dan umrah - hukum, Syarat, Rukun, Sunah Haji dan Umrah. naik haji ke Baitullah adalah rukun islam yang terakhir yang artinya berkunjung ke tanah suci untuk melaksanakan amal ibadah sesuai dengan syarat, rukun, dan waktu yang telah ditentukan. Haji dan umrah adalah menjadi salah satu bagian dari yang di urus oleh Kementerian Agama Republik Indonesia.

kebanyakan pelayanannya masih dilakukan secara manual langsung datang ke kantor dan memerlukan proses yang panjang dan cukup lama dan dari segi aplikasi yang sudah ada yaiu SISKOHAT para calon jamaah haji masih jadi satu dengan jamaah umum dari segi pelayanan dan dari segi informasi pun masih sangat minim sehingga calon jamaah yang sudah tua atau berumur masih perlu menunggu lama bertahun tahun

Metode penelitian yang digunakan yaitu observasi, wawancara dan uji pustaka. Adapun Tujuan dari penelitian ini yaitu terciptanya aplikasi yang dapat mempermudah dalam proses pengolahan data, penyimpanan data, pencarian data serta pembuatan laporan dengan sistem aplikasi berbasis web.
\end{abstract}

Kata Kunci : Aplikasi, Pelayanan Haji dan Umrah, Web

\section{PENDAHULUAN}

Permasalahan dalam

mendaftar haji saat ini membutuhkan waktu yang lama untuk antri menunggu jadwal keberangkatan calon jamaah sehingga calon jamaah yang sudah berumur (sudah tua) masih perlu menggu lama bertahun tahun. Begitu pula dalam sistem pelayananan dan pendaftaran nya masih di lakukan secara manual langsung ke kantor Kementrian Agama, kemudian dari segi pendaftaran online pun Komputerisasi Haji Terpadu (SISKOHAT) masih di jadikan satu dengan pelayanan dan pendaftaran haji umum. Hal ini yang menjadi sebuah keresahaan para calon jamaah yang sudah berumur yang 
mengkhawatirkan kesehatan mereka jika harus masih menuggu lama untuk bisa berangkat berhaji untuk menuntaskan salah satu dari rukun islam ini.

Dengan demikian dibutuhkan aplikasi yang dapat dimanfaatkan untuk mengumpulkan data, mengolah, menyimpan, melihat kembali serta menyalurkan informasi kepada siapa saja yang membutuhkan.

Hal tersebut mendorong Saya mencoba membuat sebuah aplikasi yang mampu mengolah data pelayanan maupun memberikan segi informasi untuk para calon jamaah yaitu "APLIKASI PELAYANAN PROGRAM HAJI, UMRAH PRIORITAS DAN JADWAL KEBERANGKATAN DI KANTOR KEMENTRIAN AGAMA KABUPATEN BARITO KUALA" dari adanya perancangan program ini mengutamakan khusus jamaah haji yang sudah berumur agar lebih di segerakan di berangkatkan agar tidak lama lagi menunggu antrian keberangkatan bertahun tahun lagi.

\section{METODE PENELITIAN}

Metode yang digunakan pada penelitian ini adalah Waterfall yang mempunyai enam tahapan yaitu : Rekayasa dan Pemodelan Sistem (System Engineering), Analisa Kebutuhan Perangkat Lunak (Analysis),

Gambar 1. Activity Diagram User (Jamaah)

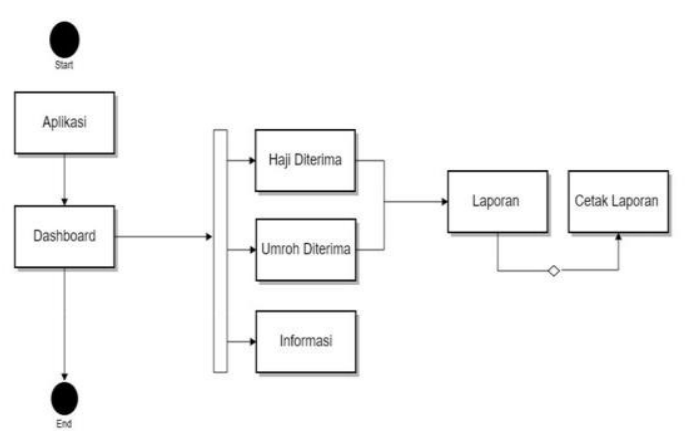

Jurnal Ilmiah “Technologia”
Perancangan Perangkat Lunak (Design), Pengkodean (Coding), Pengujian Perangkat Lunak (Testing), Pemeliharaan Perangkat Lunak (Maintenance). Teknik testing sistem menggunakan teknik Blackbox.

\section{HASIL DAN PEMBAHASAN}

Analisis sistem yang berjalan : Merupakan gambaran tentang bagaimana sistem yang sedang berjalan di Kantor Kementerian Agama Wilayah Kota Banjarmasin sebelum dibuatnya sistem, pertama untuk dari segi haji dan umrah pada saat ini masih jadi perdebatan dengan permasalahan tentang lama nya menunggu giliran untuk keberangkatan haji sehingga menjadi keresahan bagi masyarakat yang ingin berangkat haji dan umrah yang sudah tua. Kemudian dari segi pelayanan masih harus datang ke kantor untuk mengisi biodata dan pembayran segalahal untuk melengkapi segala persyaratannya, kemudian mereka harus bolak balik kekantor jika persyaratan nya masih ada yang kurang untuk melengkapinya.

Analisis kebutuhan sistem : kebutuhan data, kebutuhan antarmuka, dan kebutuhan fungsional yang diperoleh dari hasil wawancara dan observasi.
Gambar 8. Tampilan Admin Data Semua Jamaah

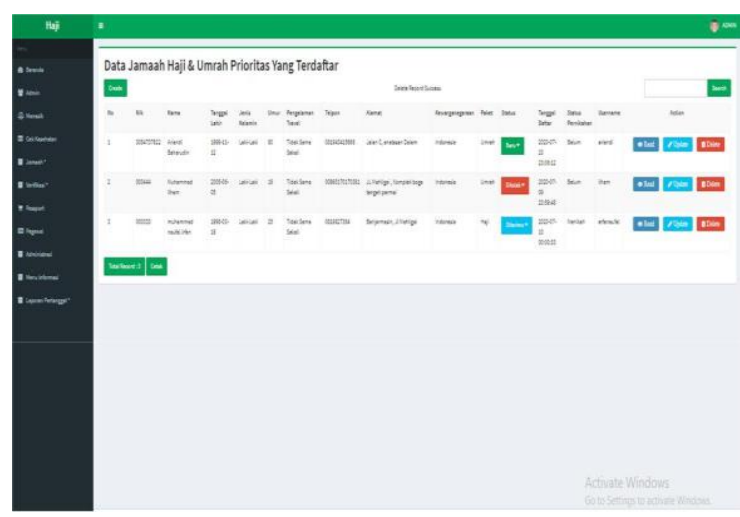


Gambar 2. Use Case Diagram

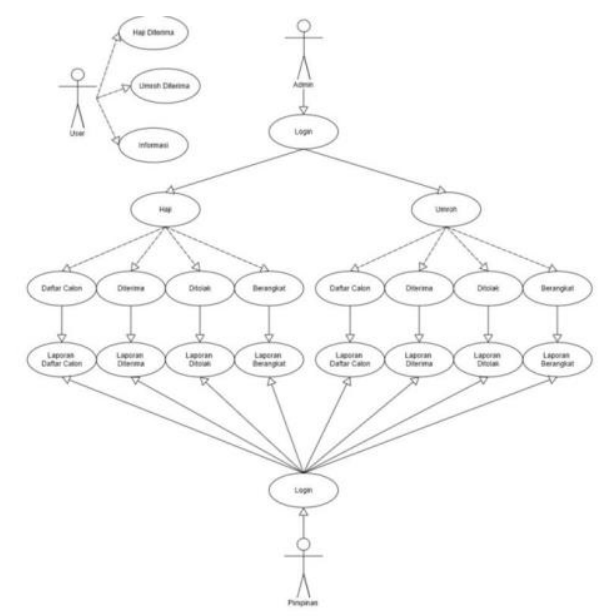

Gambar 3. Rancangan Form Data Semua Jamaah

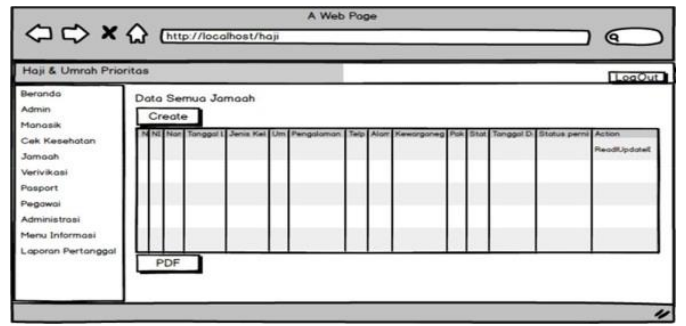

Gambar 4. Form Input Data Jamaah Baru

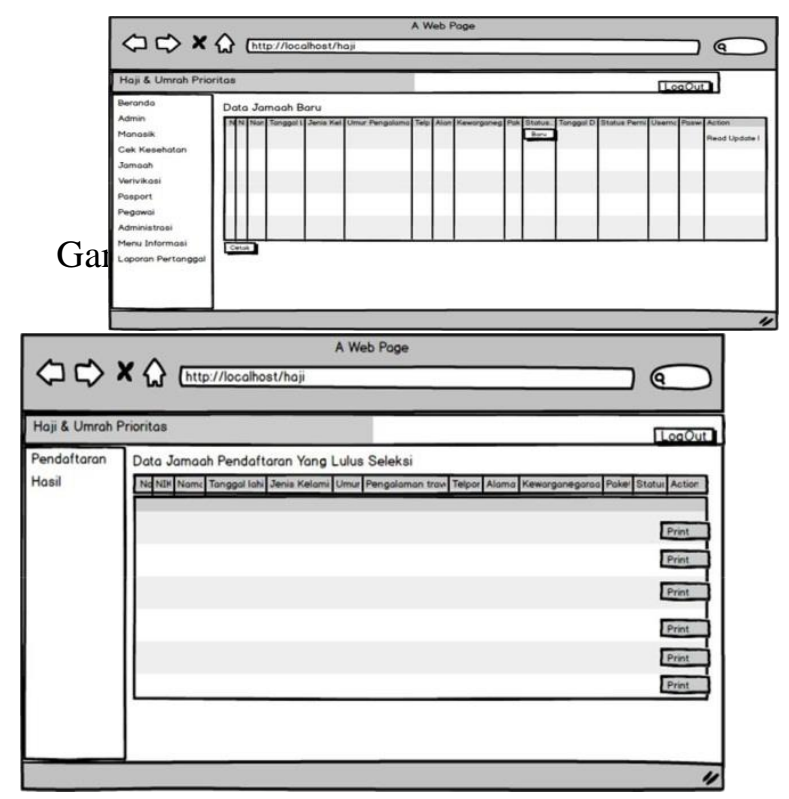

Gambar 9. Tampilan Admin Edit Data Jamaah

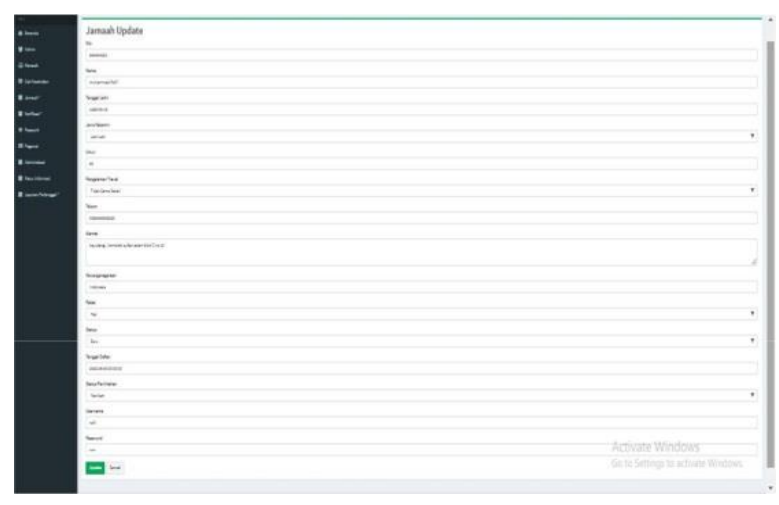

Gambar 10 Tampilan

Data Jamaah Terverifikasi

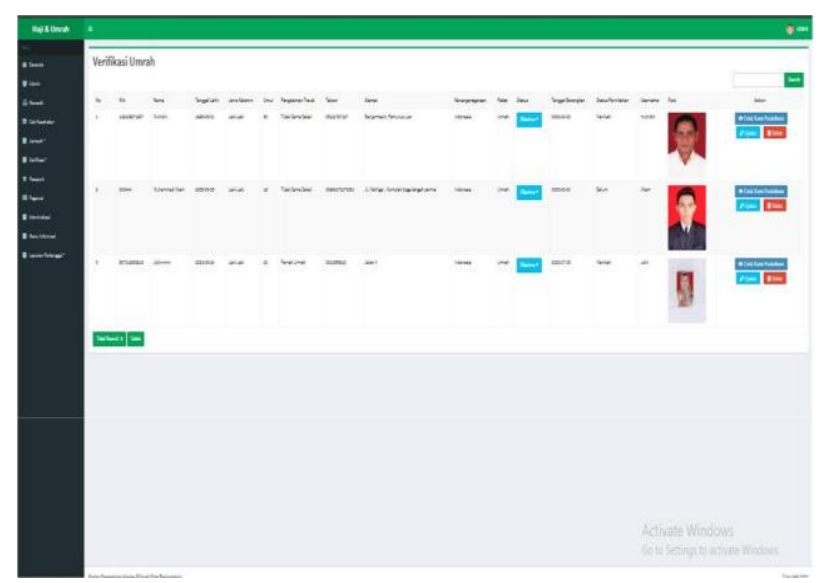

Gambar 11 Tampilan Jamaah

Data Informasi Pendaftaran

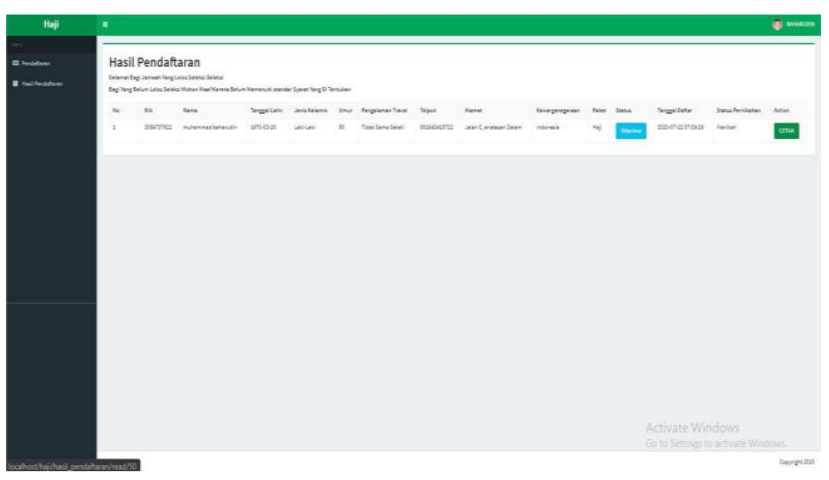

Jurnal Ilmiah "Technologia" 
Gambar 6. Form Jamaah Isi / Edit Biodata Utama

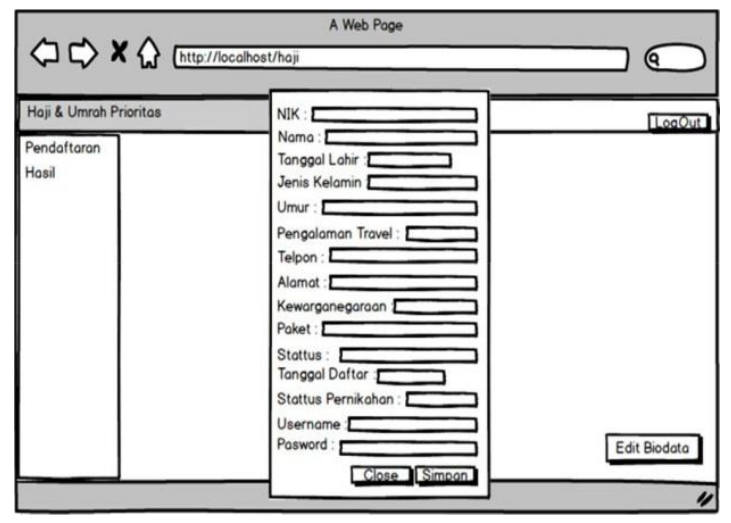

Gambar 7. Rancangan Output Admin Laporan Data Jamaah Diterima

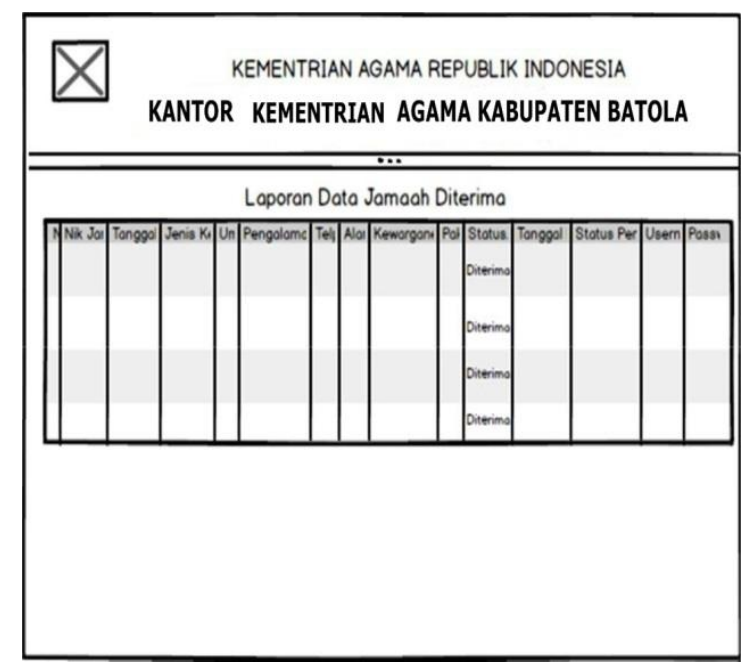

Gambar 12 Report Data Jamaah

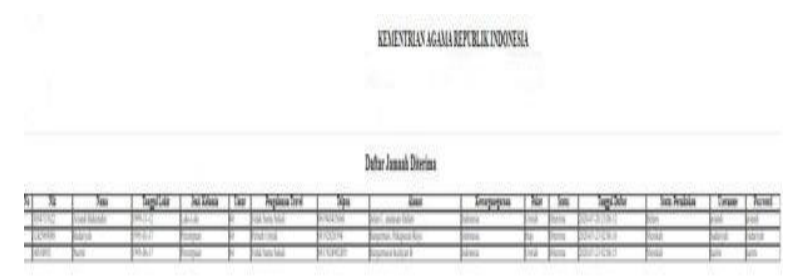

Gambar 13.

Report Hasil Pendaftaran Jamaah

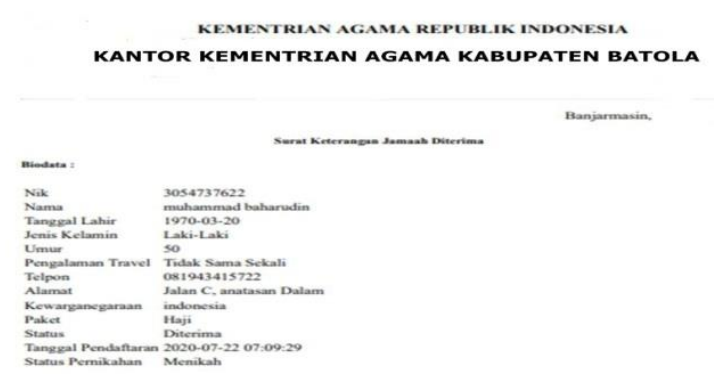

\section{KESIMPULAN}

Setelah melewati beberapa tahapan yaitu analisis sistem, desain, perancangan, pengujian dan implementasi maka dapat diambil kesimpulan bahwa Aplikasi Pelayanan Haji, Umrah Prioritas Dan Jadwal Keberangkatan Pada Kantor Kementrian Agama Wilayah Kabupaten Batola dapat memudahkan dan memberika beberapa manfaat untuk penggunanya, yaitu :
1. Hasil Perancangan ini merupakan salah satu system yang akan mempermudah jamaah haji dan umrah untuk mendaftar haji dan umrah.

2. Memudahkan para jamaah yang sudah tua agar tidak resah terlalu lama lagi menunggu dan Mempermudah dari segi pelayanan agar tidak repot bolak balik

3. Admin dan user atau calon jamaah tidak melakukan proses manual lagi dalam 
penginputan data, pencarian data, dan validasi dat sehingga data akan lebih valid dan dapat mengurangi kesalahan.

4. dari segi laporan langsung otomatis hmemfilter data yang di ingin kan maka laporan akan tercetak dan admin atau user akan mengetahui langsung.

\section{DAFTAR PUSTAKA}

[1]Andi, \& Medcoms. (2011). Aplikasi Web Database dengan Dreamweaver dan PHP-MYSQL. Yogyakarta: Andi Offset.

[2]Arief, M. R. (2011). Pemrograman Web Dinamis menggunakan PHP dan. MySQL. Yogyakarta: CV. Andi Offset.

[3]Badiyanto. (2013). Buku Pintar Framework Yii. Yogyakarta: Mediakom.

[4]Chaffey, D. (2007). E-Business and ECommerce 3td Edition. London: Prentice Hall.

[5]Daryanto. (2004). Keterampilan Dasar Pengoprasian Komputer. Bandung: Yrama Widya.

[6]Gie, T. L. (2007). Administrasi Perkantoran Modern. Yogyakarta: Liberty.

[7]Hakim,L. (2010). Membangun Web Berbasis PHP dengan Framework Codeigniter. Yogyakarta: Lokomedia.

[8]Handayaningrat, S. (1997). Pengantar Ilmu Administrasi dan Managemen. Jakarta: PT. Gunung Agung.

[9]Hidayat, R. (2010). Cara Praktis Membangun Website Gratis. Jakarta: PT. Elex Media Komputindo. 